Article

\title{
Caffeine Stabilises Fission Yeast Wee1 in a Rad24-Dependent Manner but Attenuates Its Expression in Response to DNA Damage
}

\author{
John P. Alao ${ }^{1,2, *}$, Johanna Johansson-Sjölander ${ }^{2}$, Charalampos Rallis ${ }^{1,3(\mathbb{D}}$ and Per Sunnerhagen ${ }^{2}$ \\ 1 School of Health, Sports and Bioscience, University of East London, Stratford Campus, London E15 4LZ, UK; \\ c.rallis@essex.ac.uk \\ 2 Department of Chemistry and Molecular Biology, University of Gothenburg, P.O. Box 462, \\ SE-405 30 Gothenburg, Sweden; johanna.johansson.sjolander@cmb.gu.se (J.J.-S.); \\ per.sunnerhagen@cmb.gu.se (P.S.) \\ 3 School of Life Sciences, University of Essex, Wivenhoe Park, Colchester CO4 3SQ, UK \\ * Correspondence: j.p.alao@uel.ac.uk; Tel.: +44-(0)208-223-4434
}

Received: 17 August 2020; Accepted: 24 September 2020; Published: 30 September 2020

\begin{abstract}
The widely consumed neuroactive compound caffeine has generated much interest due to its ability to override the DNA damage and replication checkpoints. Previously Rad3 and its homologues was thought to be the target of caffeine's inhibitory activity. Later findings indicate that the Target of Rapamycin Complex 1 (TORC1) is the preferred target of caffeine. Effective Cdc2 inhibition requires both the activation of the Wee1 kinase and inhibition of the Cdc25 phosphatase. The TORC1, DNA damage, and environmental stress response pathways all converge on Cdc25 and Wee1. We previously demonstrated that caffeine overrides DNA damage checkpoints by modulating Cdc25 stability. The effect of caffeine on cell cycle progression resembles that of TORC1 inhibition. Furthermore, caffeine activates the Sty1 regulated environmental stress response. Caffeine may thus modulate multiple signalling pathways that regulate Cdc25 and Wee1 levels, localisation and activity. Here we show that the activity of caffeine stabilises both Cdc25 and Wee1. The stabilising effect of caffeine and genotoxic agents on Wee1 was dependent on the Rad24 chaperone. Interestingly, caffeine inhibited the accumulation of Wee1 in response to DNA damage. Caffeine may modulate cell cycle progression through increased Cdc25 activity and Wee1 repression following DNA damage via TORC1 inhibition, as TORC1 inhibition increased DNA damage sensitivity.
\end{abstract}

Keywords: cell cycle; Schizosaccaromyces pombe; caffeine; Cdc25; Wee1; TORC1; torin1; DNA damage checkpoint

\section{Introduction}

Cell cycle progression through mitosis is under the opposing control of the Cdc25 phosphatase and the Wee1 kinase. Cdc25 removes inhibitory phosphorylation moieties on Cdc2, which in turn enhances Cdc25 activity in a positive feedback loop. In contrast, Wee1 phosphorylates Cdc2 on tyrosine residue 15 to inhibit its activity. Cdc2 in turn negatively regulates Wee1 by phosphorylation leading to its nuclear exclusion or degradation [1-3]. Cells must delay progress through S-phase and mitosis in response to stalled replication, DNA double strand breaks and other forms of damage, in order to effect DNA repair and maintain viability [4,5]. DNA damage activates the Ataxia and Telangiectasia Mutated (ATM) homologue Rad3 which in turn, activates the downstream checkpoint kinases Cds1 and Chk1 in the S- and G2- cell cycle phases respectively (Alao and Sunnerhagen, 2008). Effective activation and maintenance of DNA damage checkpoints thus involves the dual regulation of both Cdc25 and Wee1 via a "double lock" mechanism [6]. Activation of the DNA damage response pathway 
induces inhibitory Cdc25 phosphorylation, Rad24 binding, nuclear export and stockpiling within the cytoplasm. In contrast, increased Wee1 activation occurs via phosphorylation, and this kinase accumulates within the nucleus [4,5]. Caffeine has generated much controversy by its ability to override checkpoint signalling but the underlying mechanisms remain unclear. Caffeine inhibits members of the members of the phosphatidylinositol 3 kinase-like kinase (PIKK) family including ataxia telangiectasia mutated (ATM) and ataxia — and rad related (ATR) kinase homologue Rad3 and Target of Rapamycin Complex 1 (TORC1) in vitro [7-10]. Initial reports suggested that caffeine overrides DNA damage checkpoint signalling by inhibiting Schizosaccharomyces pombe Rad3 and its orthologues but this view remains controversial [11-13]. Studies that are more recent indicate that TORC1 is the major cellular target of caffeine in vivo [12,14-16]. TORC1 is a major regulator of cell cycle progression acting on both Cdc25 and Wee1. The inhibition of TORC1 activity suppresses Wee1 expression, results in increased Cdc25 activation and drives cells into mitosis. In addition, the effect of caffeine on cell cycle progression resembles that of TORC1 inhibition [17-19]. We previously demonstrated that caffeine overrides checkpoint signalling in part, by stabilising Cdc25 expression. Interestingly, deletion of the $\mathrm{rad}^{+}$gene and its downstream target Cds1 similarly resulted in Cdc25 stabilisation. These findings suggested a role of Rad3 signalling in regulating Cdc25 stability during the normal cell cycle. Similarly, the Sty1-regulated Environmental Stress Response (ESR) pathway also plays a role in regulating both Cdc25 and Wee1 expression levels and is activated by caffeine $[5,20]$. The integration of Cdc25 and Wee1 phosphorylation, localisation, stability and activity thus play a key role in modulating the timing of mitosis. TORC1, Rad3 and Sty1 regulate the major signalling pathways that converge on the Cdc25 and Wee1 axis $[3,5,17]$. Herein we further explored the mechanism (s) by which caffeine stabilises Cdc25 and overrides checkpoint signalling and have investigated the impact of subcellular localisation under these conditions. Here we report that in addition to modulating Cdc25 activity, caffeine also suppressed the DNA damage-induced stabilisation of Wee1 in S. pombe. In contrast, caffeine stabilised Wee1 in a Rad24 dependent manner under normal cell cycle conditions. These findings demonstrate that caffeine overrides the DNA damage checkpoints by positively regulating Cdc 25 and negatively regulating Wee1. They also provide further evidence for the assertion that caffeine modulates TORC1 (and other pathways) and not Rad3 signalling to overcome the DNA damage checkpoint "double lock" mechanism.

\section{Materials and Methods}

\subsection{Strains, Media and Reagents}

Strains are listed in Table 1. Cells were grown in yeast extract plus supplements medium (YES) Stock solutions of caffeine (Sigma Aldrich AB, Stockholm, Sweden) $(100 \mathrm{mM})$ were prepared in water stored at $-20^{\circ} \mathrm{C}$. $\mathrm{HU}$ (Sigma Aldrich $\mathrm{AB}$ ) was dissolved in water at a concentration of $1 \mathrm{M}$ and stored at $-20^{\circ} \mathrm{C}$. Phleomycin (Sigma Aldrich AB) was dissolved in water and stock solutions $(10 \mu \mathrm{g} / \mathrm{mL}$ ) stored at $-20^{\circ} \mathrm{C}$. Alternatively, phleomycin was purchased from Fisher scientific UK as a $20 \mathrm{mg} / \mathrm{mL}$ solution and stored at $-20^{\circ} \mathrm{C}$. Rapamycin and Torin1 (Tocris UK.) were dissolved in DMSO and stored at $-20^{\circ} \mathrm{C}$.

\subsection{Molecular Genetics}

Deletion of the open reading frames was done by PCR-based genomic targeting using a KanMX6 construct [21]. Disruptions were verified by PCR using genomic DNA extracted from mutants.

\subsection{Microscopy}

Calcofluor white (Sigma-Aldrich) staining and septation index assays were carried out as previously described $[18,22,23]$. Images were obtained with a Zeiss AxioCam on a Zeiss Axioplan 2 microscope with a $100 \times$ objective using a 4,6-diamidino-2-phenylindole (DAPI) filter set. 
Table 1. S. pombe strains.

\begin{tabular}{|c|c|}
\hline$h^{-} \mathrm{L} 972$ & Lab Stock \\
\hline$h^{+}$cdc25-6HA $\left[\mathrm{ura4}^{+}\right]$leu1-32 ura4-D18 (FY7031) & YGRC \\
\hline$h^{+}$cdc25-6HA [ura4 ${ }^{+}$] leu1-32 ura4-D18 rad24::KanMX6 & This study \\
\hline$h^{-}$cdc25-12myc::ura4 ${ }^{+}$ura4-D18 leu1-32 & P. Russell \\
\hline$h^{-}$cdc25-GFP int $c d c 25::$ ura $^{+}$ura4-D18 leu1-32 & P. Young \\
\hline$h^{+} c d c 25_{(9 A)}-G F P_{\text {int }} c d c 25::$ ura $^{+}{ }^{+}$ura4-D18 leu1-32 & P. Young \\
\hline$h^{-} c d c 25_{(12 A)}$-GFPint cdc25::ura4 $4^{+}$ura4-D18 leu1-32 & P. Young \\
\hline$h^{-}$cdc25 $(12 A)$-GFPint cdc25::ura4 ${ }^{+}$ura4-D18 leu1-32 mik1::ura4 ${ }^{+}$ & P. Young \\
\hline$h^{+}$cut8::ura4 (FY9535) & YGRC \\
\hline$h^{+}$leu1 his 2 ura4 cut8-8xMyc ura4 $4^{+}$ & YGRC \\
\hline$h^{-}$wee1::ura4 ${ }^{+}$leu1-32 ura4-D18 (FY7283) & YGRC \\
\hline$h^{-}$wee1-3HA:6His leu1-32 ura4-D18 (FY16241) & YGRC \\
\hline$h^{-}$wee1-3HA:6His leu1-32 ura4-D18 rad24::KanMX6 & This study \\
\hline$h^{-}$rad24::ura4 $4^{+}$leu1 ura4-D18 ade6-M210 (FY13517) & YGRC \\
\hline$h^{-}$mik1::ura4 leu1 ura4 (FY8317) & YGRC \\
\hline$h^{+}$ade6-M210 ura4-D18 leu1-32 gaf1::KanMX6 & Bioneer \\
\hline$h^{+}$ade6-M210 ura4-D18 leu1-32 tco89::KanMX6 & Bioneer \\
\hline$h^{+}$leu1-32 ura4-D18D pab1::kanR & D. R. Kellogg \\
\hline$h^{+}$tor $2-G 2040 D$ & J. Petersen \\
\hline
\end{tabular}

YGRC, Yeast Genetic Resource Center, Osaka, Japan.

\subsection{Fluorescence-Activated Cell Sorting (FACS)}

Cells were harvested at the desired time points, resuspended in $70 \%$ ethanol and stored at $4{ }^{\circ} \mathrm{C}$ until use. FACS analyses were performed according to the previously described protocol [18], using propidium iodide $(32 \mu \mathrm{g} / \mathrm{mL}$ ) as outlined on the Forsburg lab page (http://www-rcf.usc.edu/ forsburg/ yeast-flow-protocol.html). Flow cytometry was performed with a BD FACSAria ${ }^{\mathrm{TM}}$ cell sorting system (Becton Dickinson AB, Stockholm, Sweden).

\subsection{Immunoblotting}

Monoclonal antibodies directed against HA (F-7), Myc (9E10) and pan 14-3-3 (K-19) proteins were from Santa Cruz Biotechnology (Heidelberg, Germany). Monoclonal antibodies directed against GFP (11814460001) and $\alpha$-tubulin were from Sigma-Aldrich (Sigma Aldrich AB). Polyclonal antibodies directed against phospho-(Tyr15) Cdc2 were from Cell Signaling Technology (BioNordika, Stockholm, Sweden). Monoclonal antibodies against $\mathrm{Cdc} 2$ were from Abcam (Cambridge, UK). For immunoblotting, protein extracts were prepared as previously described [18] with addition of $1 \times$ PhosStop phosphatase inhibitor cocktail (Roche Diagnostics Scandinavia AB, Bromma, Sweden). Proteins were separated by SDS-PAGE. Epitope-tagged proteins were detected with the appropriate monoclonal antibodies.

\section{Results}

\subsection{Caffeine Stabilises Cdc25 by Inhibiting Its Nuclear Degradation}

We previously demonstrated that caffeine stabilises both wild type (wt) Cdc25-GFP int $_{\text {(int }}$ $=$ gnomically integrated) and the Cdc25(9A)-GFP $\mathrm{int}_{\text {t }}$ mutant that lacks the 9 major inhibitory phosphorylation sites and is normally degraded following exposure to genotoxic agents $[18,24,25]$. In this study, exposure to $10 \mathrm{mM}$ caffeine also stabilised the $C \mathrm{Cdc} 25_{(12 \mathrm{~A})}-\mathrm{GFP}_{\text {int }}$ mutant protein that lacks all 12 inhibitory phosphorylation sites (Figure 1A). Caffeine also stabilised Cdc25 in mik1 $\Delta$ mutants. Mik1 is required for maintenance of the replication damage checkpoint signalling in S. pombe mutants expressing Cdc25 ${ }_{(12 \mathrm{~A})}-\mathrm{GFP}_{\text {int }}[24,25]$. As observed for rad3 $\Delta$ and $c d s 1 \Delta$ mutants [18], Cdc25 appeared more stable in a mik1 $\Delta$ genetic background (Figure 1A). Caffeine also suppressed the $20 \mathrm{mM}$ hydroxyurea (HU)-induced degradation of the $\mathrm{Cdc} 25_{(12 \mathrm{~A})}-\mathrm{GFP}_{\text {int }}$ mutant (Figure 1B). Sty1 can induce Cdc25 accumulation via phosphorylation and Rad24- mediated nuclear export, causing the phosphatase 
to be sequestered within the cytoplasm where it accumulates [5]. The stabilising effect of caffeine was not due to stress-induced Sty1 activation, as exposure to $0.6 \mathrm{M} \mathrm{KCl}$ (a strong activator of Sty1 signalling) induced Cdc25 ${ }_{(9 \mathrm{~A})}-\mathrm{GFP}_{\text {int }}$ degradation (Figure 1C). Inhibition of Crm1-dependent nuclear export with $100 \mathrm{ng} / \mathrm{mL}$ leptomycin B (LMB) slightly suppressed Cdc25 levels in both wt and Cdc25 (12A)-GFP ${ }_{\text {int }}$ expressing mutants (Figure 1D). LMB also failed to induce Cdc25 ${ }_{(12 \mathrm{~A})}-\mathrm{GFP}_{\text {int }}$ accumulation under these conditions, indicating the mutant protein is degraded in the nucleus (Figure 1D). As previously reported, caffeine is more effective at overriding DNA damage checkpoints in strains expressing Cdc25 mutant protein that cannot be negatively phosphorylated (Figure 1E).

A

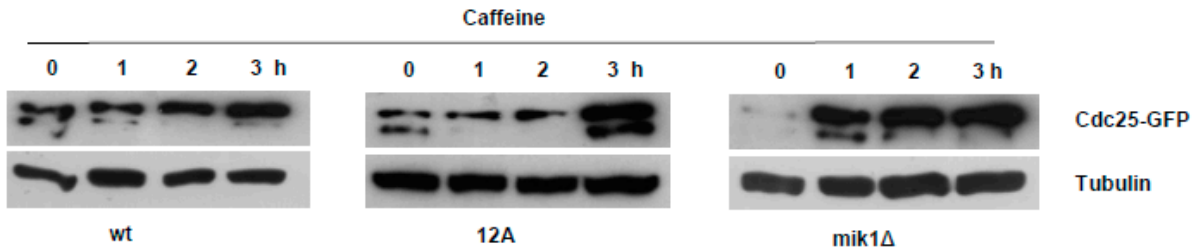

B
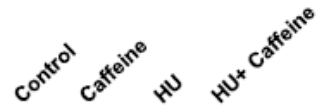

C

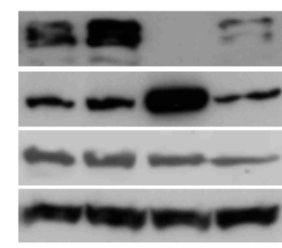

Cdc25-GFP

pCdc2

mik1 $\Delta$

Cdc25(12A) -GFPint

\section{Cdc2}

Tubulin
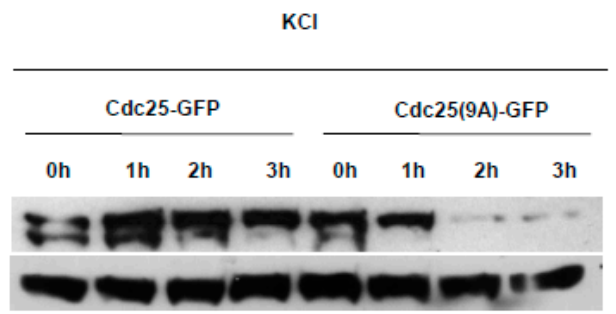

Cdc25-GFP

Tubulin

D
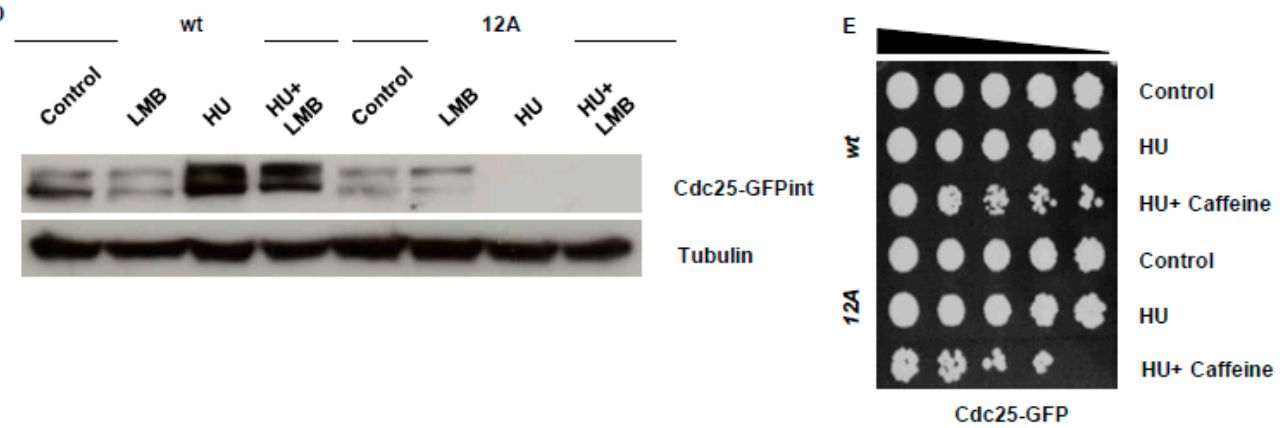

Figure 1. Caffeine induces the nuclear accumulation of Cdc25 in S. pombe. (A). Strains expressing wt Cdc25-GFP, Cdc25 $5_{(12 \mathrm{~A})}$-GFP, or Cdc25-GFP from a mik1 $\Delta$ genetic background were incubated with $10 \mathrm{mM}$ caffeine and harvested at the indicated time points. Total protein lysates were resolved by SDS-PAGE and Cdc25 detected using antibodies directed against GFP. Gel loading was monitored using antibodies directed against tubulin. (B). Strains expressing $C d c 25_{(12 A)}-G F P_{\text {int }}$ were pre-treated with $20 \mathrm{mM} H U$ for two hours, followed by the addition of $10 \mathrm{mM}$ caffeine. Cultures were incubated for a further $2 \mathrm{~h}$ and total protein lysates were resolved by SDS-PAGE. Cdc25 was detected using antibodies directed against GFP. Phospho-Cdc2 and Cdc2 were detected using antibodies directed against as indicated. Gel loading was monitored as in A. (C). Strains expressing wt Cdc25-GFP or Cdc25(9A)-GFP were cultured in YES containing $0.6 \mathrm{M} \mathrm{KCl}$ and harvested at the indicated time points. Samples were analysed as in A. (D). Strains expressing wt Cdc25-GFP or Cdc25 ${ }_{(12 \mathrm{~A})}-\mathrm{GFP}_{\text {int }}$ were incubated with $100 \mathrm{ng} / \mathrm{mL} \mathrm{LMB}$ and $20 \mathrm{mM}$ HU alone or in combination. Cells were pre-treated with HU for $2 \mathrm{~h}$ and then incubated with LMB for another $2 \mathrm{~h}$ as indicated. Samples were processed as in A. using antibodies directed against the HA epitope. Gel loading was monitored using antibodies directed against tubulin. (E). Strains expressing wt Cdc25-GFP and Cdc25(12A)-GFP int exposed to $20 \mathrm{mM} \mathrm{HU}$ alone or further incubated with $10 \mathrm{mM}$ caffeine as indicated. Samples were adjusted for relative cell numbers, serially diluted, plated on YES agar and incubated for 2-3 days. 


\subsection{Caffeine Stabilises Wee1 in a Rad24 Dependent Manner}

TORC1 inhibition activates Cdc25 and suppresses Wee1 activity [19]. As Cdc25 and Wee1 are both partially regulated by ubiquitin-dependent degradation, we next investigated the effect of caffeine on Wee1 expression. Exposure to caffeine induced a rapid and time-dependent increase in Wee1 levels. Wee1 levels increased with $30 \mathrm{~min}$ of exposure to caffeine and continued to rise over the course of the $4 \mathrm{~h}$ incubation periods (Figure 2A,B). The deletion of $\mathrm{rad} 24^{+}$resulted in a partial reduction of Wee1 expression and induced a "wee" phenotype (Figure 2C). A role for Rad24 in regulating Wee1 stability has previously been reported [20]. Caffeine may also affect the phosphorylation of Wee1 in a manner that is distinct from a general effect on protein degradation [26]. The caffeine-induced accumulation of Wee1 was dependent on Rad24 expression (Figure 2D). Exposure to LMB slightly stabilized Wee1 levels, suggesting that nuclear export plays a role in regulating the kinase's stability (Figure 2E) [26] Caffeine thus interferes with the coordinated regulation of Cdc25 and Wee1 under normal and genotoxic conditions.

A

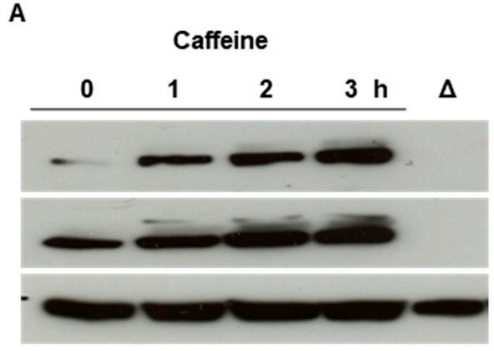

C

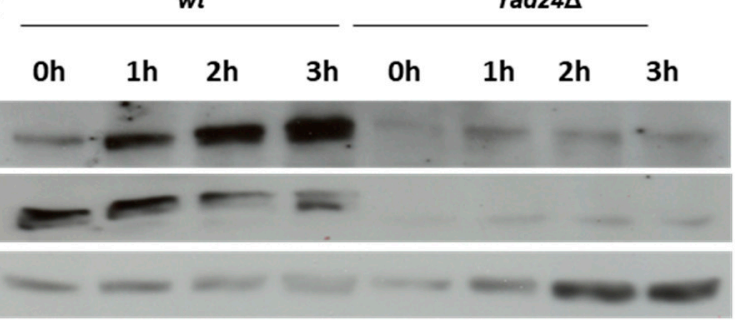

B

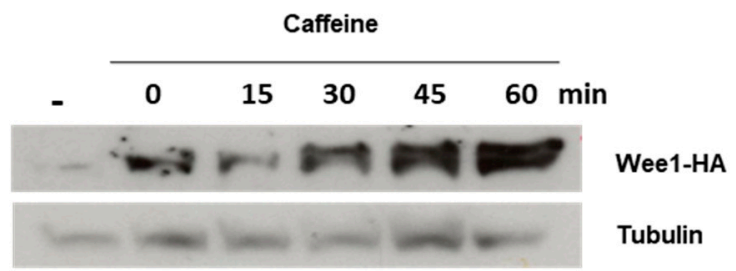

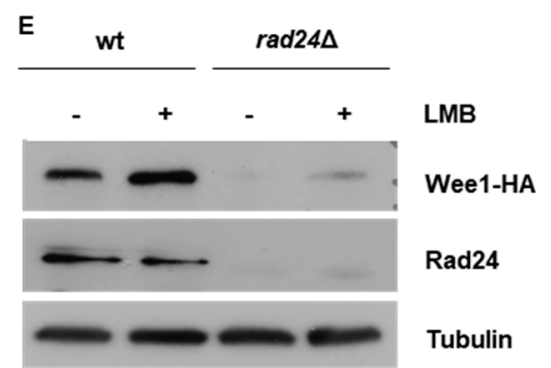

Wee1-HA

Rad24

Tubulin

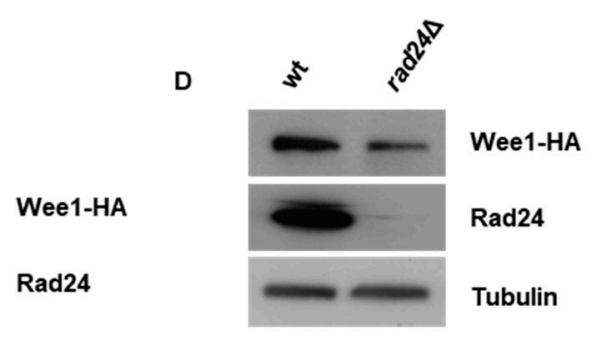

Figure 2. Caffeine induces Wee1 accumulation in a Rad24-dependent manner in S. pombe. (A). A Wee1-HA expressing strain was incubated with $10 \mathrm{mM}$ caffeine and harvested at the indicated time points. Total protein lysates were resolved by SDS-PAGE. Wee1 was detected using antibodies directed against the HA epitope. Rad24 was detected using a pan 14-3-3 antibody. A rad24 $\Delta$ mutant was used to monitor antibody specificity. Gel loading was monitored using antibodies directed against tubulin. (B). Cells expressing Wee1-HA were treated as in A. (C). Deletion of rad24 was carried out in a Wee1-HA expressing strain. Total protein lysates were resolved by SDS-PAGE and membranes probed with antibodies directed against $\mathrm{HA}$ and tubulin. (D). Wt and rad24 $\Delta$ mutant cells expressing Wee1-HA were treated as in A. (E) Wt and rad24 $\Delta$ mutant cells were exposed to $100 \mathrm{ng} / \mathrm{mL} \mathrm{LMB}$ for $2 \mathrm{~h}$. Cell lysates were treated as in D. 


\subsection{Caffeine Suppresses DNA Damage-Induced Wee1 Accumulation}

Exposure to DNA damaging agents has previously been shown to induce the accumulation of Wee1 [6]. We thus studied the effect of caffeine on Wee1 expression under these conditions. Incubation with $10 \mathrm{mM}$ caffeine alone induced the accumulation of Wee1 but had no impact on the slight suppressive effect of $20 \mathrm{mM} \mathrm{HU}$ on the protein (Figure 3A). Exposure to $10 \mu \mathrm{g} / \mathrm{mL}$ phleomycin induced Wee1 accumulation in a manner akin to that of caffeine. Interestingly, caffeine strongly inhibited phleomycin-induced Wee1 accumulation such that the levels were even below those observed in untreated cells (Figure 3A). Previous genomic screens did not identify wee1 as a transcriptional target [16] Since caffeine was added after phleomycin exposure, the lowered levels of Wee1 could reflect progression through mitosis [26] Caffeine activates both the DNA damage response and environmental stress response pathways $[18,27]$. The effect of caffeine on Wee1 stability may thus be context dependent. The loss of Wee1 expression in the presence of phleomycin would be expected to override checkpoint signalling under these conditions. Caffeine-induced Wee1 accumulation was dependent on Rad24 expression (Figure 3B). Exposure to HU in rad24 $\Delta$ mutants did not induce Wee1 accumulation, and co-exposure to caffeine completely abolished expression of this kinase. Wee1 accumulation in response to phleomycin exposure was not observed in rad $24 \Delta$ mutants. In marked contrast to wt cells, caffeine had no effect on Wee1 expression in rad24 $\Delta$ mutants exposed to phleomycin (Figure 3B). In fact, the phleomycin-induced accumulation of Wee1 did not occur in rad $24 \Delta$ mutants, identifying a direct role for Rad24 in regulating DNA damage checkpoints (Figure 3B). We next compared the effect of phleomycin exposure on Cdc2 Tyr 15 phosphorylation in wt and rad24 $\Delta$ mutants. Exposure to $10 \mu \mathrm{g} / \mathrm{mL}$ phleomycin increased the basal level of Cdc2 phosphorylation (Figure 3C). In rad24 $\Delta$ mutants, basal Cdc2 phosphorylation was not detected and exposure to phleomycin resulted in levels of Cdc2 phosphorylation below those of untreated wt cells (Figure 3C). We previously demonstrated that caffeine stabilises Cdc25 in the nucleus of $S$. pombe cells exposed to genotoxic agents [18]. Caffeine thus both stabilises Cdc25 and suppresses Wee1 expression under genotoxic conditions. This activity would effectively lead to the abolition of the "double lock" DNA damage checkpoint mechanism.
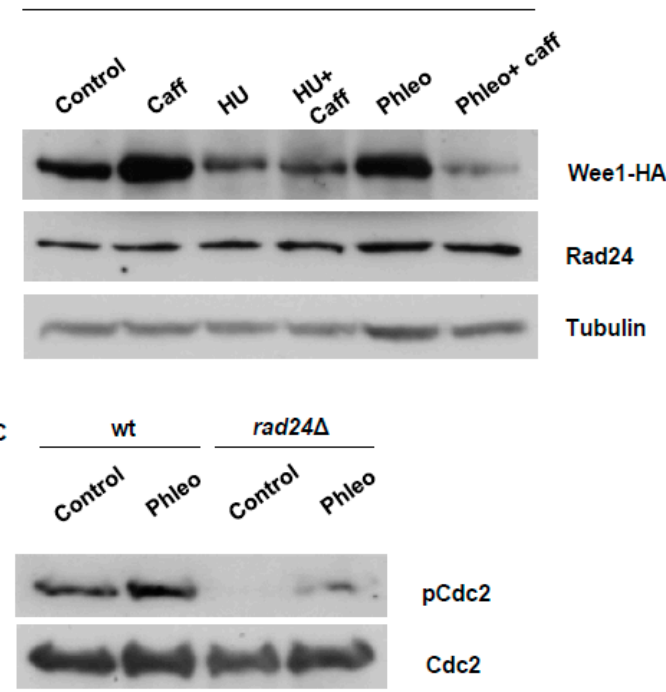

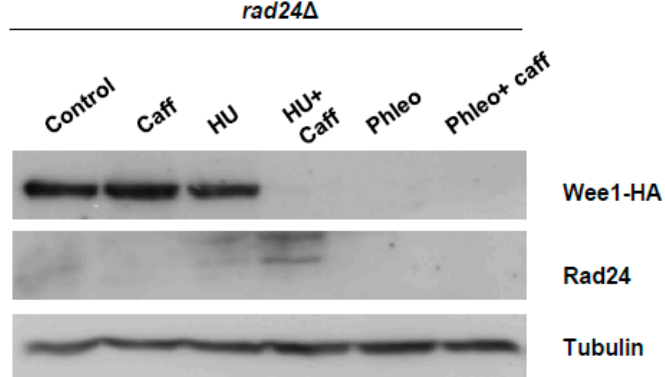

Figure 3. Caffeine suppresses genotoxin-induced Wee1 accumulation in S. pombe. (A). Cells expressing Wee1-HA were cultured with $10 \mathrm{mM}$ caffeine alone or in combination with $20 \mathrm{mM} \mathrm{HU}$ or $10 \mu \mathrm{g} / \mathrm{mL}$ phleomycin as indicated. Cultures were pre-treated with HU or phleomycin for $2 \mathrm{~h}$ and then for a further $2 \mathrm{~h}$ in the presence or absence of caffeine. (B). Wee1-HA rad24 $\Delta$ cells were treated as in A. (C). $\mathrm{Wt}$ cells expressing Wee1-HA and Wee1-HA rad24 $\Delta$ cells were exposed to $10 \mu \mathrm{g} / \mathrm{mL}$ phleomycin for $1 \mathrm{~h}$. Total protein lysates were resolved by SDS-PAGE and membranes probed with antibodies directed against phospho-Cdc2 and Cdc2. 


\subsection{Caffeine Mediates Checkpoint Override by Suppressing Wee1 under Genotoxic Conditions}

We previously observed that the effect of caffeine on cell cycle progression in S. pombe is enhanced in wee $1 \Delta$ and other checkpoint mutants [18]. Caffeine $(10 \mathrm{mM})$ overrode checkpoint signalling in wee1 $\Delta$ mutants but to a lesser extent than in wt cells (Figure 4A). As judged by FACS analyses, survival assays, and cell morphology, caffeine only slightly increases the sensitivity of wee1 $\Delta$ mutants to $20 \mathrm{mM} \mathrm{HU}$ relative to wt cells (Figure 4B-D). Interestingly, caffeine was far more effective at overriding checkpoint signalling in response to $\mathrm{HU}$ in rad24 $\Delta$ mutants (Figure $4 \mathrm{D}, \mathrm{E}$ ). We previously reported that caffeine stabilizes Cdc25, which would cannot be exported from the nucleus of rad24 $\Delta$ mutants [18].
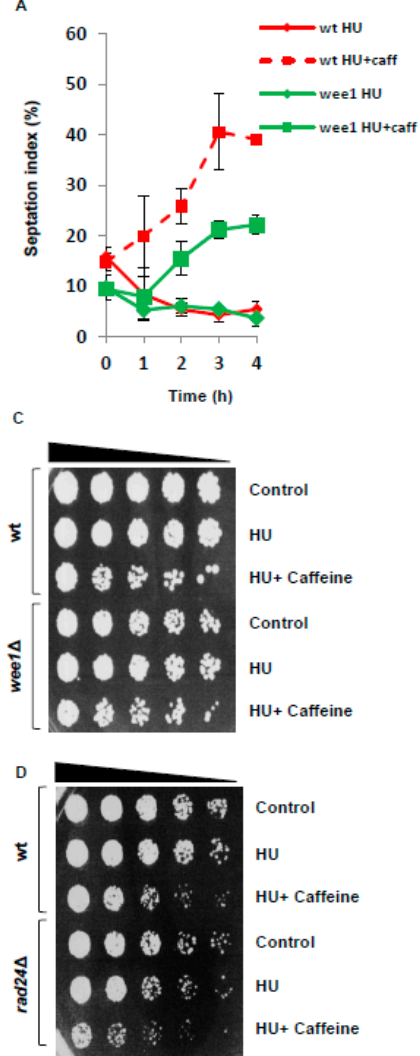

B
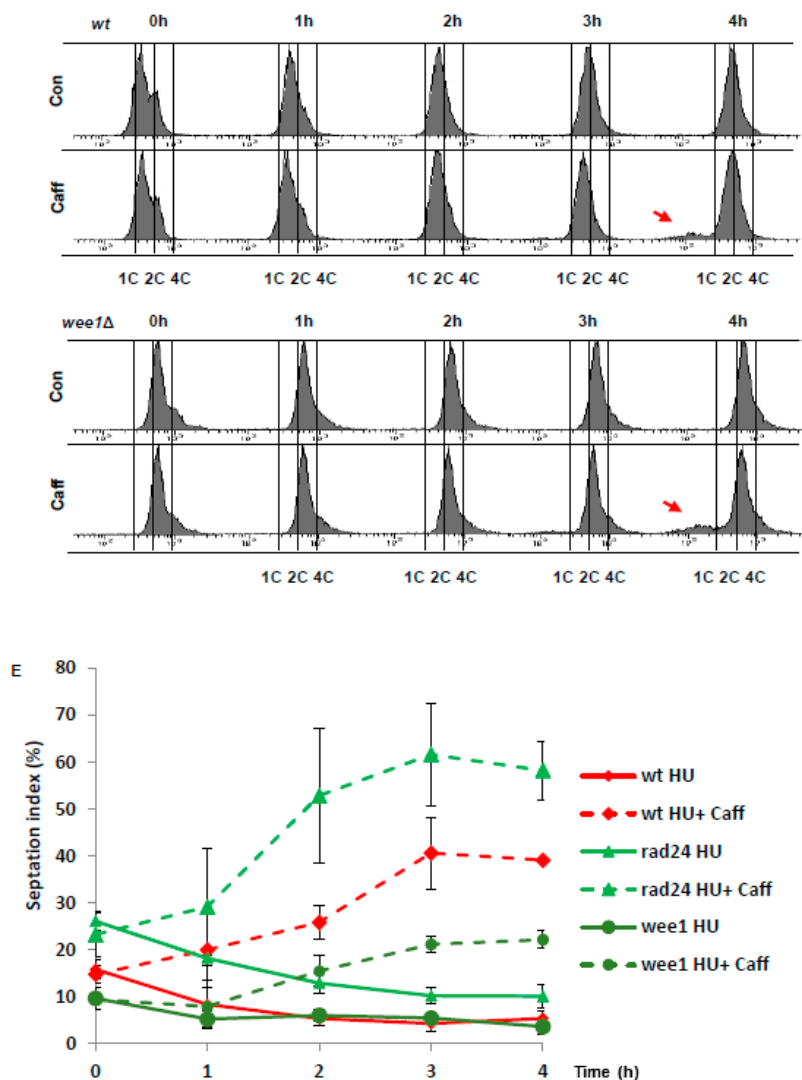

Figure 4. Differential effects of caffeine on cell cycle progression in S. pombe wee $1 \Delta$ and rad $24 \Delta$ mutants. (A). Cultures of wt and wee $1 \Delta$ cells were incubated with $10 \mu \mathrm{g} / \mathrm{mL}$ phleomycin for $2 \mathrm{~h}$. The cultures were then incubated for a further $4 \mathrm{~h}$ with or without $10 \mathrm{mM}$ caffeine and samples harvested at the indicated time points. Cells were fixed in 70\% ethanol, stained with aniline blue and the septation index determined by fluorescent microscopy. Error bars represent the S.E. of 3 experiments. (B). Samples from A were stained with propidium iodide and analysed by FACS. Arrows indicate cell with mis-segregated chromosomes. (C). Wt and wee1 $\Delta$ cells were incubated with $20 \mathrm{mM} \mathrm{HU}$ for $2 \mathrm{~h}$. The cultures were then incubated for a further $2 \mathrm{~h}$ in the presence of $10 \mathrm{mM}$ caffeine as indicated. Cultures were adjusted for relative cell numbers, serially diluted and plated unto YES agar plates. Plates were incubated at $30{ }^{\circ} \mathrm{C}$ for 2-3 days. (D). Wt and rad24 $\Delta$ cells were treated as in C. (E). Wt, rad $24 \Delta$ and wee $1 \Delta$ cells were treated as in A.

\subsection{Inhibition of TORC1 Signalling Enhances DNA Damage Sensitivity}

The TORC1 complex regulates the timing of mitosis and its inhibition by rapamycin or torin1 leads to an advanced entry into mitosis $[19,28]$. As caffeine inhibits TORC1 and advances entry into mitosis $[16,18]$, we investigated if TORC1 inhibition similarly overrides checkpoint signalling. Exposure to $20 \mathrm{mM} \mathrm{HU}$ or $7.5 \mu \mathrm{M}$ torin1 for $4 \mathrm{~h}$ did not affect the viability of wt S. pombe cells 
(Figure 5A). Unlike caffeine, co-exposure with torin1 did not affect the sensitivity of wt cells to HU (Figures 4D and 5A). Cells co-exposed to HU and torin1 were shorter than cells exposed to HU alone but no chromosome mis-segregation was observed. In contrast, cells exposed to torin1 alone displayed a "wee" phenotype (Figure 5B).

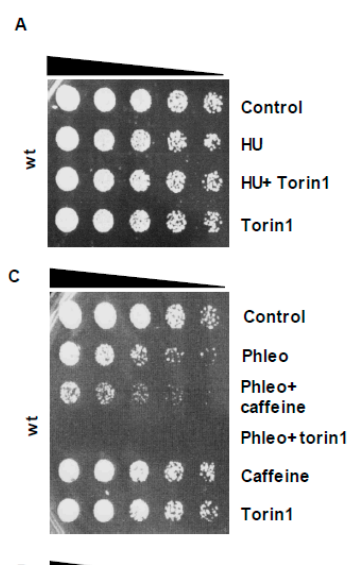

B
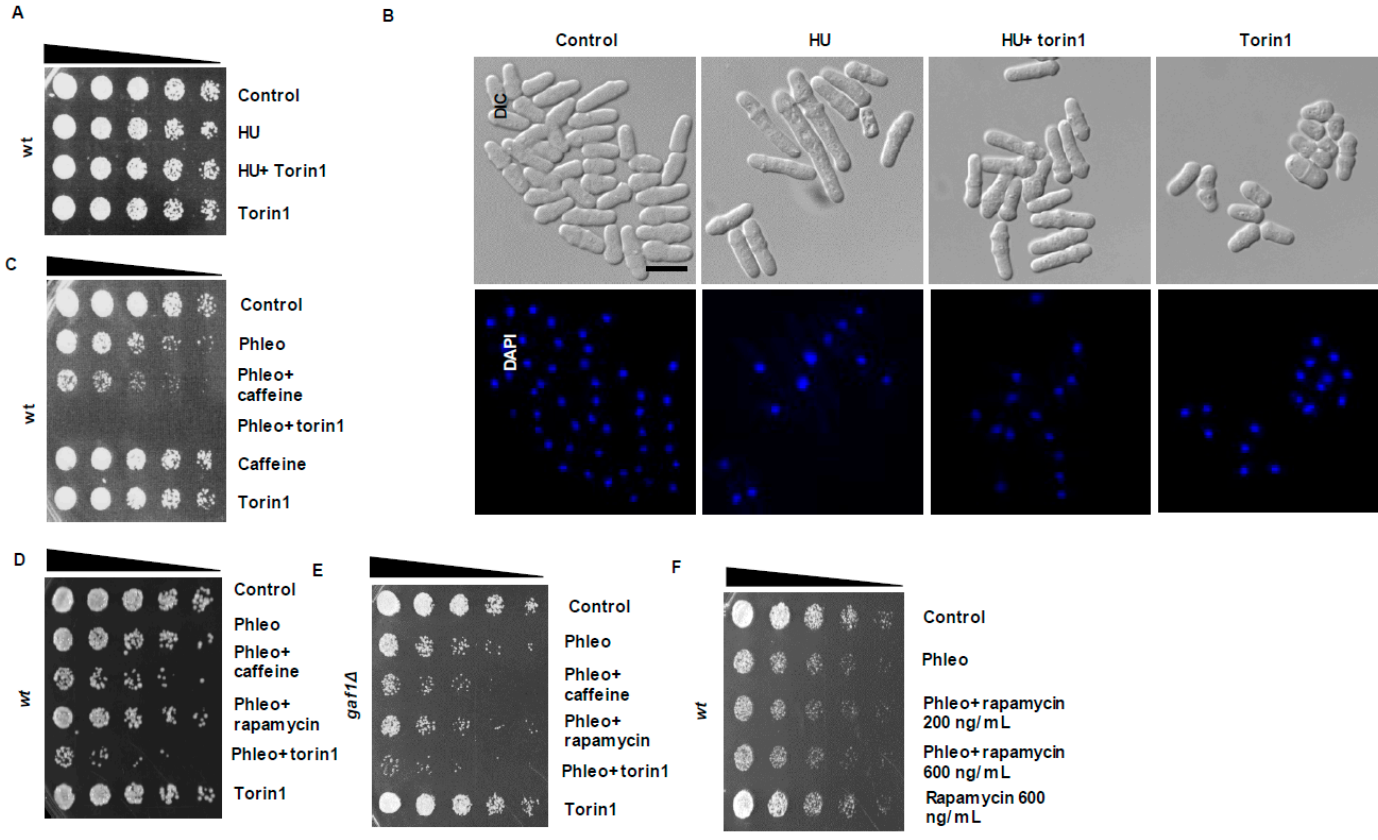

Control

Phleo

Phleo+rapamycin

$200 \mathrm{ng} / \mathrm{mL}$

Phleo+rapamycin

$600 \mathrm{ng} / \mathrm{mL}$

Rapamycin 600
$\mathrm{ng} / \mathrm{mL}$

Figure 5. Inhibition of TORC1 overrides checkpoint signalling similarly to caffeine. (A). Wt cells were incubated with $20 \mathrm{mM} \mathrm{HU}$ for $2 \mathrm{~h}$. The cultures were then incubated for a further $2 \mathrm{~h}$ in the presence of $10 \mathrm{mM}$ caffeine as indicated. Cultures were adjusted for relative cell numbers, serially diluted and plated unto YES agar plates. Plates were incubated at $30{ }^{\circ} \mathrm{C}$ for $2-3$ days. (B). Cells in A were fixed in $70 \%$ ethanol, stained with DAPI and examined by differential contrast microscopy. Scale bar $10 \mu \mathrm{M}(\mathbf{C})$. Wt cells were incubated with $10 \mu \mathrm{g} / \mathrm{mL}$ phleomycin for $2 \mathrm{~h}$. The cultures were then incubated for a further $2 \mathrm{~h}$ in the presence of $10 \mathrm{mM}$ caffeine or $7.5 \mu \mathrm{M}$ torin 1 as indicated. Cultures were adjusted for relative cell numbers, serially diluted and plated on YES agar plates. Plates were incubated at $30{ }^{\circ} \mathrm{C}$ for 2-3 days. (D). Wt cells expressing Wee1-HA, were incubated with $5 \mu \mathrm{g} / \mathrm{mL}$ of phleomycin for $2 \mathrm{~h}$. The cultures were then incubated for a further $2 \mathrm{~h}$ in the presence of $10 \mathrm{mM}$ caffeine, $200 \mathrm{ng} / \mathrm{mL}$ rapamycin or $5 \mu \mathrm{M}$ torin 1 as indicated. Cultures were adjusted for relative cell numbers, serially diluted and plated on YES agar plates. Plates were incubated at $30{ }^{\circ} \mathrm{C}$ for $2-3$ days. (E). gaf1 $\Delta$ mutant cells were incubated with $5 \mu \mathrm{g} / \mathrm{mL}$ of phleomycin for $2 \mathrm{~h}$. The cultures were then incubated for a further $2 \mathrm{~h}$ in the presence of $10 \mathrm{mM}$ caffeine, $200 \mathrm{ng} / \mathrm{mL}$ rapamycin or $5 \mu \mathrm{M}$ torin 1 as indicated. Cultures were adjusted for relative cell numbers, serially diluted and plated on YES agar plates. Plates were incubated at $30{ }^{\circ} \mathrm{C}$ for 2-3 days. (F). Wt cells were exposed to $5 \mu \mathrm{g} / \mathrm{mL}$ of phleomycin for $2 \mathrm{~h}$. The cultures were then incubated for a further $2 \mathrm{~h}$ in the presence of $200 \mathrm{ng} / \mathrm{mL}$ or $600 \mathrm{ng} / \mathrm{mL}$ rapamycin as indicated. Cells exposed to $600 \mathrm{ng} / \mathrm{mL}$ rapamycin served as a control. Cultures were adjusted for relative cell numbers, serially diluted and plated on YES agar plates. Plates were incubated at $30^{\circ} \mathrm{C}$ for $2-3$ days.

In contrast to its effects on HU sensitivity, torin1 was far more effective at sensitising wt cells to phleomycin than caffeine (Figure 5C,D). Similar results were obtained with gaf1 $\Delta$ mutants, a transcription factor that partially mediates the effect of torin1 on aging [29,30], (Figures 5E and 6B). In addition, gaf1 $\Delta$ mutants exposed to phleomycin and torin1 were shorter than cells exposed to phleomycin alone (Figure 6C). Torin1 thus enhances DNA damage sensitivity independently of Gaf1. Rapamycin failed to affect DNA damage checkpoint signalling at concentrations as high as 600 $\mathrm{ng} / \mathrm{mL}$ in wt $S$. pombe cells (Figures 5F and 6A). Tco89 is a subunit of the TORC1 complex and tco89 $\Delta$ mutants are hypersensitive to caffeine and rapamycin [15,31]. Rapamycin sensitised tco89 $\Delta$ mutants to 
phleomycin in a manner similar to caffeine (Figure 6D). Torin1 similarly sensitised tco89 $\Delta$ mutants to phleomycin (Figure 6D). Further studies demonstrated, however, that rapamycin does not enhance sensitivity to phleomycin by overriding DNA damage checkpoint signalling in wt S. pombe (Figure 6D).
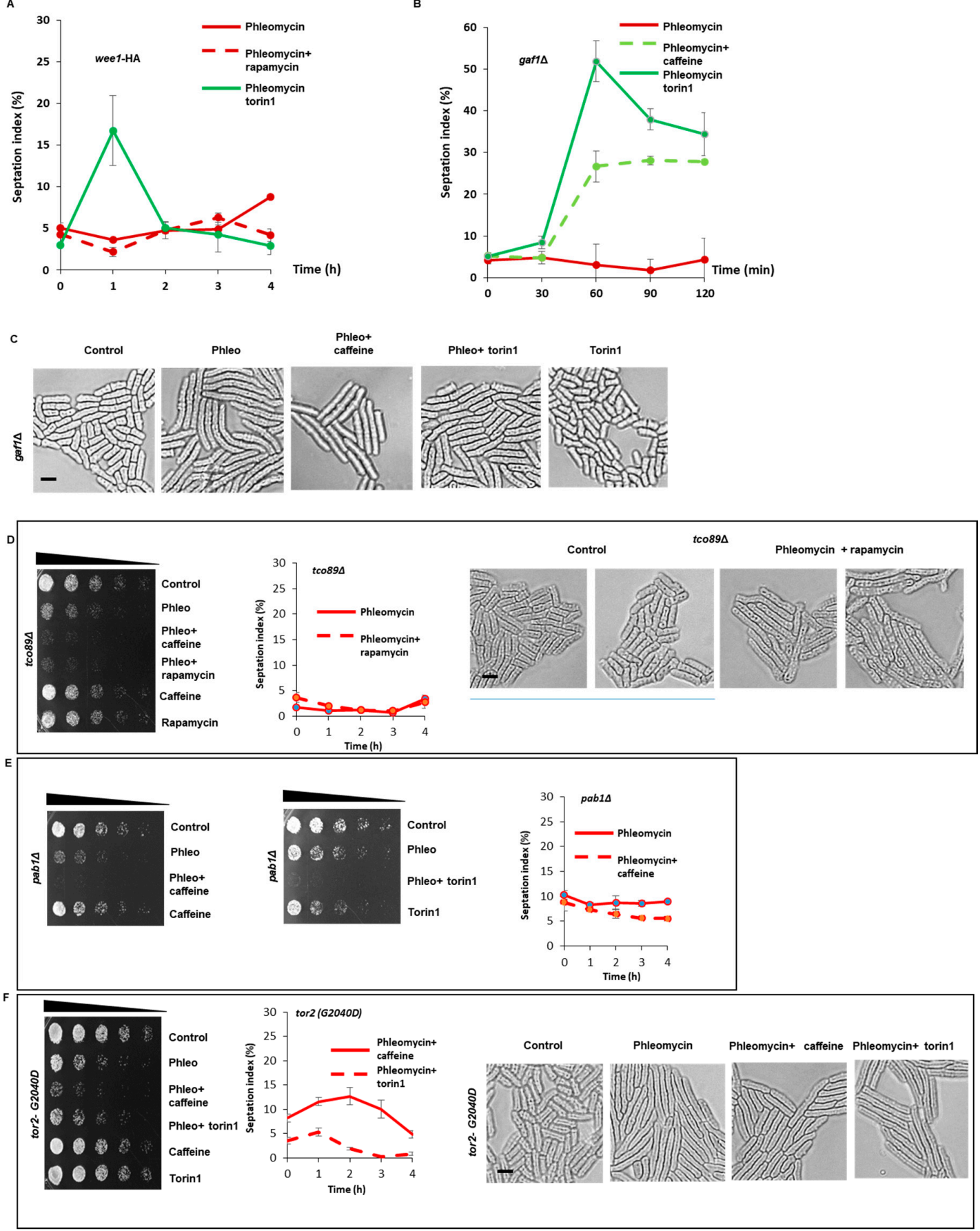

Figure 6. TORC1 inhibition by caffeine overrides checkpoint signalling similarly to caffeine. (A). Wt cells were incubated with $5 \mu \mathrm{g} / \mathrm{mL}$ of phleomycin for $2 \mathrm{~h}$. The cultures were then incubated for a further $2 \mathrm{~h}$ in the presence of $200 \mathrm{ng} / \mathrm{mL}$ rapamycin or $5 \mu \mathrm{M}$ torin1. Samples were harvested at the indicated time points. Cells were fixed in $70 \%$ ethanol, stained with calcofluor white and the septation index determined by fluorescent microscopy. (B). gaf $1 \Delta$ mutants were incubated with $5 \mu \mathrm{g} / \mathrm{mL}$ of phleomycin for $2 \mathrm{~h}$. The cultures were then incubated for a further $2 \mathrm{~h}$ in the presence of $10 \mathrm{mM}$ caffeine or $5 \mu \mathrm{M}$ torin1. Cells were fixed in $70 \%$ ethanol, stained with aniline blue or calcofluor white and the septation 
index determined by fluorescent microscopy. (C). gaf1 $\Delta$ mutants were incubated with $5 \mu \mathrm{g} / \mathrm{mL}$ of phleomycin for $2 \mathrm{~h}$. The cultures were then incubated for a further $2 \mathrm{~h}$ in the presence of $10 \mathrm{mM}$ caffeine or $5 \mu \mathrm{M}$ torin1. Cells were fixed in $70 \%$ ethanol, stained with DAPI and examined by differential contrast microscopy. Scale bar $10 \mu \mathrm{M}$ (D). tco89 $\Delta$ mutants were incubated with $5 \mu \mathrm{g} / \mathrm{mL}$ of phleomycin for $2 \mathrm{~h}$. The cultures were then incubated for a further $2 \mathrm{~h}$ in the presence of $10 \mathrm{mM}$ caffeine or $200 \mathrm{ng} / \mathrm{mL}$ rapamycin. Cultures were adjusted for relative cell numbers, serially diluted and plated on YES agar plates. Plates were incubated at $30^{\circ} \mathrm{C}$ for $2-3$ days. Alternatively, cells were treated with $10 \mathrm{mM}$ caffeine or $200 \mathrm{ng} / \mathrm{mL}$ of rapamycin alone. Samples were harvested at the indicated time points. Cells were fixed in $70 \%$ ethanol, stained with aniline blue or calcofluor white and the septation index determined by fluorescent or the relative cell lengths with differential contrast microscopy. Scale bar $10 \mu \mathrm{M}$ (E). pab1 $\Delta$ mutants were incubated with $5 \mu \mathrm{g} / \mathrm{mL}$ of phleomycin for $2 \mathrm{~h}$. The cultures were then incubated for a further $2 \mathrm{~h}$ in the presence of $10 \mathrm{mM}$ caffeine or $5 \mu \mathrm{M}$ torin1. Alternatively, cells were treated with $10 \mathrm{mM}$ caffeine or $5 \mu \mathrm{M}$ torin 1 alone. Cultures were adjusted for relative cell numbers, serially diluted and plated on YES agar plates. Plates were incubated at $30^{\circ} \mathrm{C}$ for $2-3$ days. Alternatively, samples were harvested at the indicated time points. Cells were fixed in $70 \%$ ethanol, stained with aniline blue or calcofluor white and the septation index determined by fluorescent microscopy. (F). The tor2 (G2040D) strain was incubated with $5 \mu \mathrm{g} / \mathrm{mL}$ of phleomycin for $2 \mathrm{~h}$. The cultures were then incubated for a further $2 \mathrm{~h}$ in the presence of $10 \mathrm{mM}$ caffeine or $5 \mu \mathrm{M}$ torin1. Cultures were adjusted for relative cell numbers, serially diluted and plated on YES agar plates. Plates were incubated at $30{ }^{\circ} \mathrm{C}$ for $2-3$ days. Alternatively, samples were harvested at the indicated time points. Cells were fixed in $70 \%$ ethanol, stained with aniline blue or calcofluor white and the septation index determined by fluorescent or the relative cell lengths with differential contrast microscopy. Scale bar $10 \mu \mathrm{M}$.

Active TORC1 delays the timing of mitosis, by indirectly inhibiting the PP2A phosphatase catalytic subunit Pab1. Thus, TORC1 inhibition results in advanced mitosis and a smaller cell size [32]. Caffeine and torin1 were still able to enhance sensitivity of pab1 $\Delta$ mutants to phleomycin (Figure $6 \mathrm{E}$ ). As with tco89 $\Delta$ mutants, this enhanced sensitivity to phleomycin did not result in DNA damage checkpoint override (Figure 6E). To confirm that torin1 overrides checkpoint signalling in a TORC1 resistant manner, we investigated its effect on the torin1-resistant tor2-G2040D mutant [19]. Unlike caffeine, torin1 failed to override phleomycin-induced DNA damage checkpoint signalling in the tor2-G2040D mutant (Figure 6F). Together with previous findings $[12,15,18]$, our study strongly suggests that caffeine overrides DNA damage checkpoint signalling by targeting Tor2 and the TORC1 complex. We cannot however, rule out that caffeine can enhance sensitivity to DNA damage independently of checkpoint override, as DNA repair pathways are required for resistance to the drug [27].

\section{Discussion}

The precise mechanisms whereby caffeine overrides DNA damage checkpoint signalling remain unclear. In the present study, we investigated further how caffeine modulates cell cycle progression through Cdc25 and Wee1. Recent studies suggest that the Tor2-containing TORC1 complex is the major target of caffeine in vivo [12,14-16]. We previously demonstrated that caffeine induces Cdc25 accumulation independently of Rad3 inhibition [18]. As TORC1 regulates Cdc25 and Wee1 activity and is inhibited by caffeine, this inhibition may in fact underlie the effects of the compound on cell cycle progression.

\subsection{Effect of Caffeine on Cdc25 Stability}

Cdc25 undergoes Cdc2-dependent activating phosphorylation as well as inhibitory phosphorylation via the Rad3 and Sty1 regulated signalling pathways [33,34]. Caffeine stabilises wt and Cdc25 mutant proteins that cannot be phosphorylated in response to DNA damage. Caffeine thus clearly stabilises Cdc25 independently of its negative phosphorylation. Furthermore, caffeine is more effective at stabilising the $\mathrm{Cdc} 25_{(9 \mathrm{~A})}-\mathrm{GFP}_{\text {int }}$ and $\mathrm{Cdc} 25_{(12 \mathrm{~A})}-\mathrm{GFP}_{\text {int }}$ isoforms and hence checkpoint override in these genetic backgrounds. The stabilising effect of caffeine on Cdc25 is also independent 
of Sty1 signalling, as exposure to osmotic stress induced the degradation of $\mathrm{Cdc} 25_{(9 \mathrm{~A})}-\mathrm{GFP}_{\text {int }}$. The Cdc25 $5_{(9 \mathrm{~A})}-\mathrm{GFP}_{\text {int }}$ and $\mathrm{Cdc} 25_{(12 \mathrm{~A})}-\mathrm{GFP}_{\text {int }}$ mutants are also rapidly degraded following exposure to genotoxic agents $[18,24,25]$. These conditions must thus cause cellular changes that result in the targeting of these mutants for ubiquitin-dependent degradation. Inhibition of nuclear export with LMB resulted in a decrease in Cdc25 levels and prevented its stockpiling following exposure to HU. LMB also failed to prevent the HU-induced degradation of the Cdc25 $5_{(2 \mathrm{~A})}-\mathrm{GFP}_{\text {int }}$ mutant protein. As the $\mathrm{Cdc} 25_{(12 \mathrm{~A})}-\mathrm{GFP}_{\text {int }}$ mutants cannot be exported from the nucleus, caffeine appears to partially inhibit the nuclear degradation of Cdc25 in S. pombe [18,24,25] Accordingly, Cdc25(12A)-GFP int mutants are more susceptible to caffeine-mediated checkpoint override than wt cells. It remains unclear if caffeine-induced Cdc25 accumulation results from TORC1 inhibition.

\subsection{Effect of Caffeine on Wee1 Stability}

Our previous studies suggested that Wee1 attenuates the effect of caffeine on cell cycle progression in S. pombe [18]. Furthermore, Cdc25 and Wee1 are co-regulated during the cell cycle and thus determine the timing of mitosis $[19,26]$. We thus investigated the effect of caffeine on Wee1 expression. Interestingly, caffeine induced rapid Wee1 accumulation under normal growth conditions. This accumulation was dependent on Rad24 expression which was also induced by exposure to caffeine (Figure 2A-C). Sty1 was recently shown to modulate the ratio of Cdc25 to Wee1 in a Rad24-dependent manner [20]. Deletion of $\mathrm{rad} 24^{+}$resulted in reduced Wee1 expression indicating that unlike Cdc25, Wee1 stability is dependent on Rad24 under normal cell cycle conditions (Figures 1E and 2D and refs. $[18,24,25])$. Deletion of $r a d 24^{+}$resulted in a "semi-wee" phenotype. These findings suggest that it is the lack of Wee1 expression rather than constitutively nuclear Cdc25 expression, that is responsible for the shorter length at division observed in rad24 $\Delta$ mutants (Figure 2D and ref. [35]). Inhibiting nuclear export with LMB also stabilised Wee1 independently of Rad24. Further, caffeine stabilised the Mik1 kinase, an S-phase specific inhibitor of Cdc2 [36]. Caffeine thus appears to stabilise Cdc25, Mik1 and Wee1 under normal cell cycle conditions. We previously demonstrated that the effect of caffeine on cell cycle progression is dampened by Srk1 and Wee1 activity [18]. It remains unclear if Rad24 stabilises Mik1 and how caffeine affects this interaction in the presence of stalled replication forks or DNA damage. Remarkably, the effect of caffeine on Cdc25 and Wee1 is reversed under genotoxic conditions. Under these conditions Cdc25 is normally inactivated and sequestered in the cytoplasm or degraded in the nucleus, while Wee1 becomes activated and accumulates in the nucleus [24,25]. Exposure to caffeine under these conditions results in the stabilisation of Cdc25 within the nucleus [18] and degradation of Wee1 (Figure 3A,B). Exposure to phleomycin induced Wee1 accumulation in a Rad24-dependent manner. In contrast, exposure to HU slightly reduced Wee1 expression in wt cells but not in rad $24 \Delta$ mutants. In contrast to caffeine or phleomycin exposure alone, Wee1 did not accumulate when the cells were co-exposed to both compounds. Interestingly, caffeine also abolished Wee1 expression in rad $24 \Delta$ mutants exposed to HU. It is unclear, why phleomycin but not HU induces Wee1 accumulation. Mechanical differences in the regulation of the replication and DNA damage checkpoints may partially account for the differential effect of these compounds. Additionally, Mik1 regulates checkpoint activation during S-phase, when both Cdc25 and Wee1 levels (and consequently Cdc2 activity) are relatively lower than in G2 [26,36] It should be noted however, that caffeine suppressed Wee1 expression even in cells arrested in S-phase and Wee1 stability is dependent on Rad24. It is possible that caffeine changes the phosphorylation status of Wee1, making it more suspectable to ubiquitin-dependent degradation [19,26]. Total phospho-Cdc2 levels are also suppressed in rad24 $\Delta$ mutants, consistent with a loss of Wee1 expression and a "semi-wee" phenotype. The TORC1 complex also regulates the activity of Cdc25 and Wee1 under normal cell cycle conditions to regulate the timing of mitosis [19]. Furthermore, Sty1 can modulate the relative expression levels of Cdc25 and Wee1 in a Rad24-dependent manner [20]. Crosstalk between TORC1, Sty1, and the replication checkpoint pathway has also been reported $[37,38]$. As caffeine inhibits TORC1 and activates Sty1, its effect on cell cycle progression may be context dependent and result from fundamental changes to physiological 
co-regulation of Cdc25 and Wee1. Caffeine-mediated TORC1 inhibition may also influence autophagy and 26S proteasomal degradation [39-41]. In any case, caffeine clearly abolishes Cdc25 inhibition and degradation under genotoxic conditions independently of Rad24. In contrast, Wee1 degradation may result from changes to its phosphorylation and ability to interact with Rad24. Caffeine thus overrides the DNA damage "double lock" mechanism independently of Rad3 inhibition ([18] and this study).

\subsection{Differential Effects of Caffeine on DNA Damage Resistance}

The sensitivity of $\mathrm{rad} 24 \Delta$ and wee $1 \Delta$ mutants following a $4 \mathrm{~h}$ exposure to HU was not enhanced relative to wt cells (Figure $4 \mathrm{~F}$ ). Caffeine was however no more effective at driving checkpoint override in wee1 $\Delta$ mutants exposed to HU than in wt cells. This may reflect the differential cell cycle kinetics of wee1 $1 \Delta$ mutants which delay progression through G1, because of size constrains and the more important role of Mik1 under these conditions [24,25]. Future studies will investigate the effect of caffeine on Mik1 expression in cells exposed to HU. Alternatively, the increase in Cdc25 activity induced by caffeine in a wee1 $\Delta$ background may delay progression through cytokinesis due to high Cdc2 activity. Caffeine was more effective at overriding the replication checkpoint in rad24 $\Delta$ mutants compared to wt cells. Rad24 binding and nuclear export are not required for the inhibition of Cdc25 activity. Caffeine overrides checkpoints more efficiently in mutants expressing Cdc25 isoforms that cannot be phosphorylated [18]. It remains unclear if Rad24 stabilises Mik1 in a manner like Wee1. Increased nuclear levels of Cdc25, following exposure to HU combined with decreased Mik1 expression, might account for the greater effect of caffeine on rad24 $\Delta$ mutants. Caffeine may also suppress Mik1 expression similarly to Wee1 [42]. The sensitivity of rad24 $\Delta$ and wee1 $\Delta$ mutants to phleomycin was identical, probably reflecting the lack of Wee1 expression in these genetic backgrounds.

\subsection{TORC1 Inhibition Enhances DNA Damage Sensitivity}

Recent studies have suggested that TORC1 and not Rad3 and its homologues is the preferred target of caffeine in vitro $[12,15,18]$. TORC1 regulates the timing of mitosis by regulating the activity of the PP2A phosphatase, which in turn regulates the activity of Cdc25 and Wee1 [19,32]. Exposure of $S$. pombe cells to rapamycin or torin1, activates Cdc25 and suppresses the expression of Wee1, resulting in advanced entry into mitosis. Furthermore, the effect of caffeine on cell cycle progression mimics that of rapamycin and torin 1 and is dependent of Cdc25 [18,19]. We thus hypothesised that TORC1 inhibition by rapamycin or torin1 should override DNA damage checkpoint signalling in a manner akin to caffeine. In wt, caffeine, rapamycin and torin 1 all advance the timing of mitosis under normal cell cycle conditions in $S$. pombe $[18,19]$. In this study, caffeine and torin1 but not rapamycin sensitivity to phleomycin-induced DNA damage. Interestingly torin1 did not enhance sensitivity to $\mathrm{HU}$ in this context. This may be due to differential effects of caffeine on additional signalling pathways (e.g., Mik1 expression and global 26S proteasome-mediated protein degradation [42]. The TORC1 downstream transcription factor Gaf1 has recently been shown to mediate the effects of Tor2 inhibition on chronological lifespan in S. pombe [29,30]. Caffeine and torin1 clearly increased sensitivity to phleomycin in gaf1 $\Delta$ mutants, suggesting this effect occurs independently of Gaf1. Rapamycin could enhance sensitivity to the tco89 $\Delta$ mutant which displays enhanced sensitivity to the drug and other genotoxins $[43,44]$. This activity was not associated with DNA damage checkpoint override. TORC1 inhibition results in advanced entry into mitosis via indirect inhibition of the PP2A phosphatase and its Pab1 activating subunit [19,32]. Caffeine and torin1 enhanced DNA sensitivity in a pab1 $\Delta$ genetic background, albeit independently of checkpoint override. These observations suggest that caffeine and torin1 induce checkpoint override in wt but not pab1 $\Delta$ mutants. The increased sensitivity to DNA damage in these genetic backgrounds suggests that caffeine, and by implication torin1, can enhance sensitivity to genotoxins independently of checkpoint override. Indeed, resistance to caffeine requires Rad3 and downstream modulators of DNA damage repair such as Rhp51 and Rhp54 [27]. Our finding, that caffeine but not torin1 overrides checkpoint signalling in the torin1 
resistant tor2-G2040D mutant [19] confirms that TORC1 inhibition overrides checkpoint signalling in the presence of genotoxins.

Effective G2 checkpoint activation requires the dual inhibition of Cdc25 and activation of Wee1 [6]. Mutants that fail to express wee1 and rad24 are especially sensitive to DNA damage as these genes regulate the G2 checkpoint. Both rapamycin and torin1 suppress Wee1 expression in S. pombe, although rapamycin is less effective in this regard [19]. We have demonstrated that caffeine induces Wee1 expression under normal cell cycle conditions in a Rad24-dependent manner. Curiously, this effect is reversed under genotoxic conditions, where co-exposure to caffeine prevents Wee1 accumulation. The failure of rapamycin to override checkpoint signalling may thus result from its less effective inhibition of TORC1 and Wee1 suppression relative to torin 1 and caffeine. Indeed, rapamycin effectively overrode DNA damage checkpoint signalling in tco89 $\Delta$ mutants that display hypersensitivity to the inhibitor [15,31]. Taken together our finding and those of others, strongly suggest that caffeine overrides DNA damage signalling independently of Rad3 by inhibiting TORC1 activity.

Author Contributions: J.P.A., C.R. and P.S. conceived and designed the study. J.P.A. and J.J.-S. carried out experiments and analyzed the data. J.P.A. wrote the manuscript. All authors read, revised and approved the final manuscript. All authors have read and agreed to the published version of the manuscript.

Funding: This work was financially supported by Carl Trygger's Foundation (CTS 15:13) and the Swedish Cancer Fund (16-0708 and 19-0133). CR acknowledges funding from UEL QR funds and the Royal Society Research Award [grant number RGS \R1\201348].

Acknowledgments: We are grateful to S. Ali, R. Lucena, D.R. Kellogg and J. Petersen for technical support.

Conflicts of Interest: The authors declare no conflict of interests. The funders had no role in the design of the study; in the collection, analyses, or interpretation of data; in the writing of the manuscript, or in the decision to publish the results.

\section{References}

1. Caspari, T.; Hilditch, V. Two distinct Cdc2 pools regulate cell cycle progression and the DNA damage response in the fission yeast S. pombe. PLoS ONE 2015, 10, e0130748. [CrossRef] [PubMed]

2. Moseley, J.B. Wee1 and Cdc25: Tools, pathways, mechanisms, questions. Cell Cycle 2017, 16, 599-600. [CrossRef] [PubMed]

3. de Gooijer, M.C.; van den Top, A.; Bockaj, I.; Beijnen, J.H.; Wurdinger, T.; van Tellingen, O. The G2 checkpoint-a node-based molecular switch. FEBS Open Bio 2017, 7, 439-455. [CrossRef] [PubMed]

4. Karlsson-Rosenthal, C.; Millar, J.B. Cdc25: Mechanisms of checkpoint inhibition and recovery. Trends Cell Biol. 2006, 16, 285-292. [CrossRef]

5. Alao, J.P.; Sunnerhagen, P. Rad3 and Sty1 function in Schizosaccharomyes pombe: An integrated response to DNA damage and environmental stress? Mol. Microbiol. 2008, 68, 246-254. [CrossRef]

6. Raleigh, J.M.; O'Connell, M.J. The G(2) DNA damage checkpoint targets both Wee1 and Cdc25. J. Cell Sci. 2000, 113, 1727-1736.

7. Humphrey, T. DNA damage and cell cycle control in Schizosaccharomyces pombe. Mutat. Res. 2000, 451, 211-226. [CrossRef]

8. Bode, A.M.; Dong, Z. The enigmatic effects of caffeine in cell cycle and cancer. Cancer Lett. 2007, 247, 26-39. [CrossRef]

9. Lovejoy, C.A.; Cortez, D. Common mechanisms of PIKK regulation. DNA Repair 2009, 8, 1004-1008. [CrossRef]

10. Gibbs, B.F.; Silva, I.G.; Prokhorov, A.; Abooali, M.; Yasinska, I.M.; Casely-Hayford, M.A.; Berger, S.M.; Fasler-Kan, E.; Sumbayev, V.V. Caffeine affects the biological responses of human hematopoietic cells of myeloid lineage via downregulation of the mTOR pathway and xanthine oxidase activity. Oncotarget 2015, 6, 28678-28692. [CrossRef]

11. Moser, B.A.; Brondello, J.M.; Baber-Furnari, B.; Russell, P. Mechanism of caffeine-induced checkpoint override in fission yeast. Mol. Cell. Biol. 2000, 20, 4288-4294. [CrossRef] [PubMed]

12. Wanke, V.; Cameroni, E.; Uotila, A.; Piccolis, M.; Urban, J.; Loewith, R.; De Virgilio, C. Caffeine extends yeast lifespan by targeting TORC1. Mol. Microbiol. 2008, 69, 277-285. [CrossRef] 
13. Cortez, D. Caffeine inhibits checkpoint responses without inhibiting the ataxia-telangiectasia-mutated (ATM) and ATM- and Rad3-related (ATR) protein kinases. J. Biol. Chem. 2003, 278, 37139-37145. [CrossRef] [PubMed]

14. Kuranda, K.; Leberre, V.; Sokol, S.; Palamarczyk, G.; Francois, J. Investigating the caffeine effects in the yeast Saccharomyces cerevisiae brings new insights into the connection between TOR, PKC and Ras/cAMP signalling pathways. Mol. Microbiol. 2006, 61, 1147-1166. [CrossRef] [PubMed]

15. Reinke, A.; Chen, J.C.; Aronova, S.; Powers, T. Caffeine targets TOR complex I and provides evidence for a regulatory link between the FRB and kinase domains of Tor1p. J. Biol. Chem. 2006, 281, 31616-31626. [CrossRef] [PubMed]

16. Rallis, C.; Codlin, S.; Bähler, J. TORC1 signaling inhibition by rapamycin and caffeine affect lifespan, global gene expression, and cell proliferation of fission yeast. Aging Cell 2013, 12, 563-573. [CrossRef] [PubMed]

17. Petersen, J. TOR signalling regulates mitotic commitment through stress-activated MAPK and Polo kinase in response to nutrient stress. Biochem. Soc. Trans. 2009, 37, 273-277. [CrossRef]

18. Alao, J.P.; Johansson-Sjölander, J.; Baar, J.; Özbaki-Yagan, N.; Kakoschky, B.; Sunnerhagen, P. Caffeine stabilizes Cdc25 independently of Rad3 in Schizosaccharomyces pombe contributing to checkpoint override. Mol. Microbiol. 2014, 92, 777-796. [CrossRef] [PubMed]

19. Atkin, J.; Halova, L.; Ferguson, J.; Hitchin, J.R.; Lichawska-Cieslar, A.; Jordan, A.M.; Pines, J.; Wellbrock, C.; Petersen, J. Torin1-mediated TOR kinase inhibition reduces Wee1 levels and advances mitotic commitment in fission yeast and HeLa cells. J. Cell Sci. 2014, 127, 1346-1356. [CrossRef]

20. Paul, M.; Ghosal, A.; Bandyopadhyay, S.; Selvam, U.; Rai, N.; Sundaram, G. The fission yeast MAPK Spc1 senses perturbations in Cdc25 and Wee1 activities and targets Rad24 to restore this balance. Yeast 2018, 35, 261-271. [CrossRef]

21. Bähler, J.; Wu, J.Q.; Longtine, M.S.; Shah, N.G.; McKenzie, A., 3rd; Steever, A.B.; Wach, A.; Philippsen, P.; Pringle, J.R. Heterologous modules for efficient and versatile PCR-based gene targeting in Schizosaccharomyces pombe. Yeast 1998, 14, 943-951. [CrossRef]

22. Dunaway, S.; Walworth, N.C. Assaying the DNA damage checkpoint in fission yeast. Methods 2004, 33, 260-263. [CrossRef] [PubMed]

23. Forsburg, S.L.; Rhind, N. Basic methods for fission yeast. Yeast 2006, 23, 173-183. [CrossRef] [PubMed]

24. Frazer, C.; Young, P.G. Redundant mechanisms prevent mitotic entry following replication arrest in the absence of Cdc25 hyper-phosphorylation in fission yeast. PLoS ONE 2011, 6, e21348. [CrossRef]

25. Frazer, C.; Young, P.G. Carboxy-terminal phosphorylation sites in Cdc25 contribute to enforcement of the DNA damage and replication checkpoints in fission yeast. Curr. Genet. 2012, 58, 217-234. [CrossRef]

26. Lucena, R.; Alcaide-Gavilan, M.; Anastasia, S.D.; Kellogg, D.R. Wee1 and Cdc25 are controlled by conserved PP2A-dependent mechanisms in fission yeast. Cell Cycle 2017, 16, 428-435. [CrossRef]

27. Calvo, I.A.; Gabrielli, N.; Iglesias-Baena, I.; Garcia-Santamarina, S.; Hoe, K.L.; Kim, D.U.; Sanso, M.; Zuin, A.; Perez, P.; Ayte, J.; et al. Genome-wide screen of genes required for caffeine tolerance in fission yeast. PLoS ONE 2009, 4, e6619. [CrossRef]

28. Petersen, J.; Nurse, P. TOR signalling regulates mitotic commitment through the stress MAP kinase pathway and the Polo and Cdc2 kinases. Nat. Cell Biol. 2007, 9, 1263-1272. [CrossRef]

29. Laor, D.; Cohen, A.; Kupiec, M.; Weisman, R. TORC1 regulates developmental responses to nitrogen stress via regulation of the GATA transcription factor Gaf1. mBio 2015, 6, e00959. [CrossRef]

30. Rodríguez-López, M.; Gonzalez, S.; Hillson, O.; Tunnacliffe, E.; Codlin, S.; Tallada, V.A.; Bähler, J.; Rallis, C. The GATA transcription factor Gaf1 represses tRNA genes, inhibits growth, and extends chronological lifespan downstream of fission yeast TORC1. Cell Rep. 2020, 30, 3240-3249.e4. [CrossRef]

31. Hayashi, T.; Hatanaka, M.; Nagao, K.; Nakaseko, Y.; Kanoh, J.; Kokubu, A.; Ebe, M.; Yanagida, M. Rapamycin sensitivity of the Schizosaccharomyces pombe tor2 mutant and organization of two highly phosphorylated TOR complexes by specific and common subunits. Genes Cells 2007, 12, 1357-1370. [CrossRef] [PubMed]

32. Martin, R.; Lopez-Aviles, S. Express yourself: How PP2A-B55(Pab1) helps TORC1 talk to TORC2. Curr. Genet. 2018, 64, 43-51. [CrossRef] [PubMed]

33. Jimenez, G.; Yucel, J.; Rowley, R.; Subramani, S. The rad3+ gene of Schizosaccharomyces pombe is involved in multiple checkpoint functions and in DNA repair. Proc. Natl. Acad. Sci. USA 1992, 89, 4952-4956. [CrossRef] [PubMed]

34. Perry, J.A.; Kornbluth, S. Cdc25 and Wee1: Analogous opposites? Cell Div. 2007, 2, 12. [CrossRef] 
35. Ford, J.C.; Al-Khodairy, F.; Fotou, E.; Sheldrick, K.S.; Griffiths, D.J.F.; Carr, A.M. 14-3-3 protein homologs required for the DNA damage checkpoint in fission yeast. Science 1994, 265, 533-535. [CrossRef]

36. Lundgren, K.; Walworth, N.; Booher, R.; Dembski, M.; Kirschner, M.; Beach, D. Mik1 and Wee1 cooperate in the inhibitory tyrosine phosphorylation of Cdc2. Cell 1991, 64, 1111-1122. [CrossRef]

37. Hartmuth, S.; Petersen, J. Fission yeast Tor1 functions as part of TORC1 to control mitotic entry through the stress MAPK pathway following nutrient stress. J. Cell Sci. 2009, 122, 1737-1746. [CrossRef]

38. Fletcher, J.; Griffiths, L.; Caspari, T. Nutrient limitation inactivates Mrc1-to-Cds1 checkpoint signalling in Schizosaccharomyces pombe. Cells 2018, 7, 15. [CrossRef]

39. Gressner, O.A. About coffee, cappuccino and connective tissue growth factor-Or how to protect your liver!? Environ. Toxicol. Pharmacol. 2009, 28, 1-10. [CrossRef]

40. Marshall, R.S.; Vierstra, R.D. Eat or be eaten: The autophagic plight of inactive 26S proteasomes. Autophagy 2015, 11, 1927-1928. [CrossRef]

41. Zhao, J.; Zhai, B.; Gygi, S.P.; Goldberg, A.L. mTOR inhibition activates overall protein degradation by the ubiquitin proteasome system as well as by autophagy. Proc. Natl. Acad. Sci. USA 2015, 112, 15790-15797. [CrossRef] [PubMed]

42. Alao, J.P.; Sunnerhagen, P.; University of Gothenburg, Gothenburg, Sweden. Unpublished work. 2020.

43. Nakashima, A.; Otsubo, Y.; Yamashita, A.; Sato, T.; Yamamoto, M.; Tamanoi, F. Psk1, an AGC kinase family member in fission yeast, is directly phosphorylated and controlled by TORC1 and functions as S6 kinase. J. Cell Sci. 2012, 125, 5840-5849. [CrossRef] [PubMed]

44. Pan, X.; Lei, B.; Zhou, N.; Feng, B.; Yao, W.; Zhao, X.; Yu, Y.; Lu, H. Identification of novel genes involved in DNA damage response by screening a genome-wide Schizosaccharomyces pombe deletion library. BMC Genom. 2012, 13, 662. [CrossRef] [PubMed]

(C) 2020 by the authors. Licensee MDPI, Basel, Switzerland. This article is an open access article distributed under the terms and conditions of the Creative Commons Attribution (CC BY) license (http://creativecommons.org/licenses/by/4.0/). 